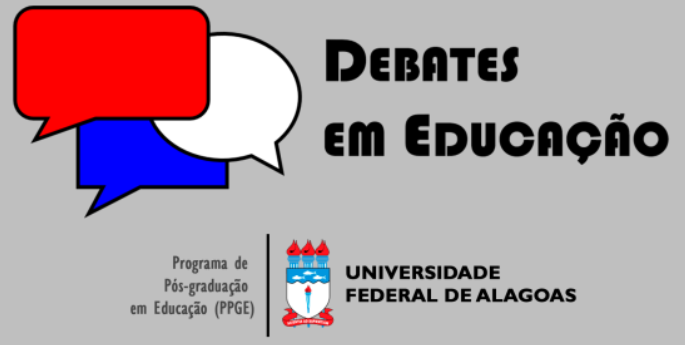

ISSN Eletrônico 2175-6600

Vol. I I | No. 23 | Jan./Abr. | 2019

Rebeca de Alcântara e Silva Meijer

Universidade da Integração Internacional da Lusofonia Afro-Brasileira (UNILAB)

rebeca.ameijer@unilab.edu.br

\section{A FORMAÇÃO DOCENTE AFROCENTRADA DA UNILAB: O SABER DOCENTE ANCESTRAL NO ENSINO DE DIDÁTICA NOS PAÍSES DA INTEGRAÇÃO}

\section{RESUMO}

Como integrante da comissão de elaboração do primeiro projeto político pedagógico do curso de Pedagogia, respondi pela proposição da componente curricular Didática nos Países da Integração, obrigatória para os cursos de licenciatura da UNILAB. Após alguns anos de experiência com o seu ensino, interessa-me fazer algumas reflexões sobre seu desenvolvimento, desafios e possibilidades no âmbito da perspectiva afrocêntrica do curso de Pedagogia. Em destaque abordo a concepção de saberes docentes ancestrais que venho propondo, resultado da valorização dos saberes dos antepassados afro-brasileiros e africanos presentes na formação cultural dos discentes de didática nos países da integração da Unilab.

Palavras-chave: Didática. Ensino. Países da integração. Saberes ancestrais. Unilab.

\section{THE AFROCENTERED TEACHING TRAINING OF UNILAB: THE ANCESTRAL TEACHING KNOWLEDGE IN THE TEACHING OF DIDACTICS IN THE INTEGRATION COUNTRIES}

\section{ABSTRACT}

As a member of the committee to prepare the first political pedagogical project of the pedagogy course, I responded by proposing the curricular component Didactics in the Integration Countries, which is compulsory for undergraduate courses at UNILAB. After a few years of experience with his teaching, I am interested in making some reflections about his development, challenges and possibilities within the Afrocentric perspective of the pedagogy course. In particular, I approach the conception of ancestral teaching knowledge that I have been proposing, a result of the valorization of the knowledge of the Afro-Brazilian and African ancestors present in the cultural formation of the didactic students in the Unilab integration countries.

Keywords: Didactics. Teaching. Integration Countries. Ancestral knowledge. Unilab.

Submetido em: 07/10/2018

Aceito em: 04/04/2019

Ahead of print em: I / $/ 04 / 2019$

Publicado em: 25/04/2019

do http://dx.doi.org/| 0.28998/2 |75-6600.20 I 9v I In23p598-6I| 


\section{APRESENTAÇÃO}

A universidade da Integração Internacional da Lusofonia Afro-Brasileira (UNILAB) é uma instituição de ensino superior da autarquia federal, criada pela Lei n 12.289/20 10 e ligada ao Ministério da educação. A Unilab foi criada e vocacionada para a cooperação internacional fundamentando suas ações no intercâmbio acadêmico e solidário com os demais países membros da Comunidade dos Países de Língua Portuguesa (CPLP), especialmente os países africanos, notadamente Angola, Cabo Verde, Guiné-Bissau, Moçambique e São Tomé e Príncipe. Frente a essa especificidade, foi criada em 2014 uma comissão para elaborar o projeto político pedagógico e curricular do curso de Pedagogia. $\bigcirc$ desafio era elaborar uma proposta de formação de pedagogos vocacionada para o que a comissão convencionou chamar de países da integração! .

O primeiro passo foi escolher a matriz epistemológica. Essa não foi uma tarefa fácil e nem pacífica, já que esse exercício é de natureza política e curricular, logo uma questão de saber e poder. $\bigcirc$ argumento de romper com a tendência eurocentrada histórica na formação de professores ganhou corpo e a proposta afrocentrada foi a matriz selecionada para a construção da base formativa de professores na Unilab. Não é por menos que o objetivo geral do curso de Licenciatura em Pedagogia da UNILAB é:

Formar para o exercício da Pedagogia, no sentido da produção e disseminação de conhecimento, na perspectiva de uma epistemologia da África e de suas diásporas, anti-racista e anti-colonial, promotora da efetiva valorização dos saberes científicos e ancestrais, com ênfase nos países que compõem a Integração Internacional da Lusofonia Afro-brasileira (UNILAB. PPC do curso de Pedagogia, 2014, p.38).

Tendo a afrocentricidade como base epistemológica é que elaboramos alguns componentes curriculares inéditos, porque enraizados na perspectiva, a saber: Filosofia da Ancestralidade e Educação, Psicologia africana da educação, Fundamentos filosóficos e práticos da capoeira, Religiosidade de matriz africana no Brasil, Políticas curriculares e descolonização dos currículos, Didática nos países da Integração.

No âmbito da ciranda curricular apresentada, contribuo diretamente em didática nos países da integração. É um desafio imenso formar a partir de uma teoria do ensino que se pretenda descolonizadora e que pense o ensinar nos países da integração da Unilab. Não nos interessa uma didática à brasileira, transladada para os países africanos de língua portuguesa, uma vez que seria, do meu ponto de vista, uma recolonização de suas práticas pedagógicas, a partir do retorno dos egressos do curso de Pedagogia a seus países. E é assim que didaticamos, buscando teorizar sobre o ensino a partir dos países integrados.

Na ementa do componente didática nos países da integração está previsto como conteúdo os saberes docentes necessários ao professorar. Tendo como aporte as pesquisas que venho desenvolvendo

\footnotetext{
' Países de língua portuguesa integrantes do acordo de cooperação internacional, notadamente do continente africano.
} 
desde 2005 sobre formação de professores, saberes docentes e a implementação da Lei n 10.639/2003² nas escolas e no currículo das licenciaturas, desenvolvi o conceito de saberes docentes ancestrais, como saber necessário para o professorar na contemporaneidade. Atualmente estou coordenando uma pesquisa financiada pela Fundação Cearense de Apoio ao Desenvolvimento Científico e Tecnológico (FUNCAP) nessa perspectiva, o que vem fundamentando as práticas pedagógicas no ensino da didática nos países da integração.

É a partir desse chão reflexivo que organizei esse trabalho. $\bigcirc$ objetivo é socializar os resultados dos processos de ensino-aprendizagem conseguidos a partir da concepção de saberes docentes ancestrais. Trata-se de uma modalidade de saber docente resultante do exercício da valorização dos saberes dos antepassados afro-brasileiros e africanos presentes na formação cultural dos discentes de didática nos países da integração da Unilab. Apresento algumas práticas pedagógicas realizadas como possibilidades para o desenvolvimento de uma educação descolonizante, comprometida com a implementação da Lei 10.639/2003 e enraizada em fundamentação afrocêntrica.

\section{REVISÃo BIBLIOGRÁFICA}

\section{I Afrocentricidade na Formação de professores}

O que é mesmo a afrocentricidade? $\bigcirc$ que quer e o que pode um curso de Pedagogia em perspectiva afrocentrada? A proposta está em conformidade com as diretrizes curriculares nacionais do curso de Pedagogia? Um curso assim idealizado é reconhecido pelo Ministério da Educação? Qual a influência da afrocentricidade na formação profissional dos egressos? Estas indagações são corriqueiras para nós docentes e discentes. Estamos acostumadas/os aos questionamentos. Afinal a afrocentricidade não é ainda uma abordagem muito conhecida e tampouco compreendida para muitos de nós. Além de que, acredito que não há abordagem que caiba inteira em um projeto de ação educativa. Assim, apresentarei aspectos da abordagem afrocêntrica que influenciam os objetivos de formação docente do curso de licenciatura Pedagogia da Unilab.

Em primeiro lugar é importante regressarmos à década de 1960 nos Estados Unidos, quando do surgimento dos estudos acadêmicos popularizados como Africana. Os protagonistas foram intelectuais e ativistas afro-americanos na luta por políticas inclusivas. Desse contexto emergiu um novo campo de conhecimento crítico aos estudos africanos tradicionalmente realizados por intelectuais brancos apontados como estudiosos que viam nos africanos e afro-americanos objetos de pesquisa. "Estudos Africana" foi

\footnotetext{
2 Trata da obrigatoriedade do ensino da História e da Cultura afro-brasileira e africana nas escolas da educação básica no Brasil.
} 
assim idealizado no plural em latim para denominar a amplitude da área de estudo, interessada na investigação dos povos e pelos povos africanos e afro-diaspóricos em qualquer lugar do mundo, além da utilização de metodologias multidisciplinares e transdisciplinares integrando as mais diversas áreas do saber.

Na Filadélfia da década de 1980 surge o primeiro programa de doutorado em estudos africana, no âmbito da Universidade Temple, idealizado e dirigido pelo professor Doutor Molefi Kete Asante, propositor do paradigma da afrocentricidade. Apesar de ter esse marco histórico, o pensamento afrocêntrico já vinha sendo elaborado em pesquisas, mesmo sem ser assim denominado, desde o século XIX e por grandes nomes, como a exemplo do intelectual senegalês Cheikh Anta Diop.

$\mathrm{Na}$ expectativa de apresentar a ideia afrocêntrica, recorro ao próprio Molefi Kete Asante quando afirma que "a afrocentricidade é um tipo de pensamento, prática e perspectiva que percebe os africanos como sujeitos e agentes de fenômenos, atuando sobre sua própria imagem cultural e de acordo com seus próprios interesses humanos" (2009, p. 93).

Elisa Larkin Nascimento (2009) adverte que a abordagem definitivamente não se apoia em conceitos biológicos de raça, como algumas críticas polêmicas afirmam. Diz que o pensar afrocêntrico entende os fenômenos a partir da identidade do sujeito, do seu centro, da sua visão de mundo, a exemplo da perspectiva do teatro experimental do negro no Brasil. Aliás, o pensar a partir do seu lugar de fala é uma tendência mundial do século XX, um exercício anticolonialista.

Em destaque também a contribuição de Ama Mazama (2009a), ao afirmar que a afrocentricidade é uma resposta à supremacia branca e que seus critérios de autodefinição devem ser extraídos da cultura africana. Pontua o aspecto cognitivo do paradigma afrocêntrico quando a afrocentricidade questiona as nossas maneiras de mobilizar a realidade. Ou seja, nossa maneira de ser, de existir está enraizada em que valores, tradições e referências? Priorizamos como ponto de partida valores e ideias da África? Mazama faz a seguinte exposição de características das culturas africanas, como elementos a se considerar no paradigma afrocentrado: "I) centralidade da comunidade; 2) respeito a tradição; 3) alto nível de espiritualidade e envolvimento ético; 4) harmonia com a natureza; 5) natureza social da identidade individual; 6) veneração dos ancestrais; 7) unidade do ser" (209, p. I I7b). E finalmente toca na questão da metodologia e do método afrocêtricos advertindo que a produção acadêmica afrocentrada deve refletir a antologia, axiologia, cosmologia, estética dentre muitos outros elementos, do povo africano, acentando-se em suas experiências. Entende que o método afrocêntrico deve considerar e refletir a primazia do espiritual ou integrar os princípios físicos e espirituais em sua dinâmica (2009, p. I23c). 


\subsection{A pretagogia como sul teórico-metodológico}

Trata-se de um jovem referencial teórico-metodológico. Ele vem acontecendo há algum tempo e envolve um coletivo de pessoas, pesquisas, práticas pedagógicas, atividades e eventos tendo como orientadora e coordenadora a professora doutora Sandra Petit da Faculdade de Educação da Universidade Federal do Ceará (UFC). A pretagogia é um referencial teórico-metodológico criado para o ensino da História e da cultura africana e dos afrodescendentes (PETIT, 20 I 5). Seus fundamentos surgem a partir do trabalho de professores, ativistas do movimento negro e intelectuais ligados direta ou indiretamente ao Núcleo de Estudo das Africanidades Cearenses (NACE), um Núcleo de Estudo Afro-brasileiro, ligado à Faculdade de Educação da UFC.

A pretagogia também é uma Pedagogia que nasce do entrelaçar de raízes-saberes teóricasmetodologias de muitos colaboradores e colaboradoras. Mas foi apenas pela ocasião do I Curso de Especialização em História e Cultura Africana e dos Afrodescendentes, voltado à formação de Professores de Quilombos no Ceará, um curso de especialização realizado pelo NACE, que esses mestres griot reúnem suas experiências, ou suas raízes-saberes. $\bigcirc$ artigo Pret@gogia: referencial teórico-metodológico para o ensino da história e cultura africana e dos afrodescendentes, reúne essas influências em torno da pretagogia e foi escrito por Sandra Haydèe Petit e Geranilde Costa e Silva (20 I I), principais organizadoras do curso de especialização. Essa abordagem, que foi criada por uma comunidade inteira de aprendentes de griot, no sentido dado pela didática afrocentrada, é assim apresentada por duas de suas criadoras:

[...] criamos o referencial da pretagogia a partir dos elementos da cosmovisão africana, porque compreendemos que para tratar das particularidades das expressões das afrodescendentes, seja necessário buscar as bases conceituais e filosóficas de origem materna, na mãe África (201 I, p. 82).

Ela vem se constituindo em abordagem afrocentrada para a formação de professores. Suas raízes estão fincadas no solo da cosmovisão africana e a partir dessa visão de mundo a pretagogia apresenta os seguintes princípios suleadores: I) o autocenhecer-se afrodescendente assumindo as raízes africanas na nossa constituição como pessoa; 2) a apropriação da ancestralidade africana, em respeito ao aprendizado transmitido pelos mais velhos, os antepassados e aos mortos; 3) a religiosidade de matriz africana como fundamento da cultura brasileira, forma de perceber a realidade a partir dos ritos dessas religiões, percepções que estão impregnadas no imaginário coletivo do povo brasileiro em forma de força vital ou axé; 4) o reconhecimento da sacralidade como elemento e princípio de todos os saberes das culturas de matriz africana, levando o desenvolvimento da espiritualidade e, consequentemente, ao respeito para com a natureza; 5) o corpo como fonte primeira de conhecimento e produtor de saberes; 6) a tradição oral como a maneira privilegiada de apropriação e de produção do conhecimento, por meio da oralidade, da 
experiência e da vibração dos seres na natureza; 6) a circularidade na relação entre os seres, os tempos e as coisas, a exemplo da ethos ubuntu, afirmando a relação comunitária que deve permanecer viva entre todos nós e em todos os espaços; 7) a noção de território como uma complexa rede de relações transversalizadas pelo tempo, a natureza e os seres pelo princípio da sacralidade; 8) o lugar social historicamente atribuído ao negro afetado pelo racismo estrutural (PETIT, 20 I 5).

No doutorado, procurei contribuir tecendo dispositivos metodológicos e reflexões extraída das produções da pesquisa com o propósito de produzir uma didática mais adequada para a pretagogia e outras abordagens descolonizadoras e de valorização da história e da cultura africana e afro-brasileira. A tese é uma grande narrativa, valorizando a tradição oral e é protagonizada pela menina negra Dadá, dentre outros personagens. Na tese há a seguinte pergunta feita a mim por dois personagens: "- Mas qual sua influência direta na construção dessa Pedagogia?" - perguntaram-me as duas crianças quase que ao mesmo tempo.

Respondi que, desde a graduação, quando pesquisei sobre racismo na escola, venho elaborando estratégias para trabalhar com temas de interesse da população negra, junto com Sandra Petit. Na pósgraduação, eu e Sandra, mais uma vez, resolvemos investir em formação inicial de professores, a primeira formação realizada na Faculdade de Educação sobre a implementação da Lei 10.639/2003.

Quando defendi a dissertação, a primeira sobre esse tema orientada por Sandra, ela prosseguiu com o interesse de continuar pesquisando, orientando, ensinando sobre a temática. Muitas outras orientações, desejos, negritudes, africanidades envolveram-na. Ela passou por enraizamentos na Faculdade de Educação (FACED) até culminar na coordenação da Especialização para Professores de Quilombo.

Após o mestrado, decidi continuar os estudos no âmbito do doutoramento, quando pesquisei a valorização da cosmovisão africana na escola a partir da pesquisa-ação e da pesquisa-formação, Meijer (20/2), construindo em coletividade com professores da educação básica, metodologias problematizadoras de uma nova teoria sobre o ensino, atravessadas pelos princípios da pretagogia.

\subsection{Didática nos países da integração}

Compreendo a profissão docente como um exercício humano de imortalidade. Ao professorarmos deixamos fatalmente nossa existência permanecer viva no processo de ensinoaprendizagem. Ser imortalizado nos traz uma responsabilidade gigantesca, porque implica o impacto que nossas práticas pedagógicas terão na/no ser humano que nossas/os alunas/os serão. Perceber a docência nessa perspectiva é assumir que estamos a tratar de uma profissão que exige excelência para seu exercício. Não é por menos que, no universo da docência no ensino superior, dedico especial atenção ao trato 
político, técnico e humano que tem o componente curricular Didática na Unilab, uma vez que a temos como uma das principais responsáveis pela construção da identidade docente.

Um dos expoentes do campo da Didática no Brasil é o brasileiro José Carlos Libâneo, que na Obra "Didática" diz que "a didática trata da teoria geral do ensino" e que tem estreita ligação com os demais campos de formação em Pedagogia, a exemplo da filosofia da educação, ao problematizar em que consiste o ato educativo (1994, p. 26).

O clássico "A didática em questão", organizado pela professora Vera Lúcia Candau, reúne trabalhos importantes na renovação do pensamento didático na década de 1980, quando a educação, a exemplo da nação brasileira, estava voltando a viver a democracia após anos de repressão. O primeiro artigo dessa obra é da própria organizadora que anuncia os rumos da didática nos novos tempos da história da educação e no âmbito da formação de professores. Para Candau (1994b), a didática estava deixando de ser meramente instrumental, quando se reduzia a ensinar receitas para a obtenção do sucesso do processo de ensino-aprendizagem, para se tornar fundamental:

A perspectiva fundamental da didática assume a multidimensionalidade do processo de ensinoaprendizagem e coloca a articulação das três dimensões, técnica, humana e política no centro configurador de sua temática. [...] Procura partir da análise da prática de sua temática. [...] Discute a questão do currículo em sua interação com uma população concreta e suas exigências, etc. (1994c).

Sendo a didática a área da Pedagogia preocupada em problematizar o ato de ensinar, na Unilab essa componente curricular também se estrutura a partir do paradigma afrocentrado, por isso recebe o nome de didática nos países da integração. Cabe-nos o compromisso de formar para a docência enraizadas/os em uma teoria sobre o ensino capaz de pensar a partir de África e da diáspora, com ênfase nos países de língua portuguesa e, de forma mais específica, na realidade dos países dos alunos presentes no coletivo de aprendizagem. Se temos participantes angolanos, brasileiros e guineenses, por exemplo, estes países terão maior atenção de nossa parte.

A didática fundamental se tornou mais engajada e preocupada com as ações educativas vivas e atuantes do processo de ensino-aprendizagem. Ficou mais atenta à relação teoria-prática. Se tornou parceira dos rumos da construção social do currículo, ou seja, das problemáticas e necessidades da sociedade transformadas em conteúdos de ensino-aprendizagem.

A didática fundamental abriu múltiplas possibilidades para a ciência da educação contemporânea. Ela transita no meio social das incertezas, onde as verdades são relativas e a ciência é só mais uma narrativa da realidade. Ela se fez presente quando os movimentos sociais, representantes dos subalternizados, derrubaram várias muralhas e marcham rumo aos espaços de poder e decisão. A didática fundamental está presente em tempos onde as informações nascem na revolução comunicacional, onde as notícias circulam em tempo real e podem ser difundidas e escutadas por todos os segmentos, não há como silenciar o 
insilenciável. E as demandas e reivindicações são muitas, assim como a pressão às respostas. As notícias correm rápidas e, mais rapidamente ainda, as mobilizações ocorrem. Bandeiras contra a intolerância, violência, discriminação, preconceito a colonização. Vozes em favor dos segmentos LGBT, pretos, pobres, mulheres, indígenas, quilombolas. Como ignorar o contemporâneo, seus fenômenos e apelos? A didática teve que dar respostas aos fenômenos atuais nos espaços de formação.

Nesse sentido, nos interessa problematizar a partir da integração entre a visão de mundo africana e afro-diaspórica os conteúdos historicamente elaborados sobre teoria do ensino no Ocidente planetário. As práticas pedagógicas estão resultando em discentes comprometidos com a descolonização da vida, das mentes, da escola e da educação em geral.

Frente a esse cenário, atravessado por tudo que representa o contemporâneo, o que pode a didática? As possibilidades são muitas e desafiadoras. Cada um, a partir de seu lugar de fala, de conhecimento e de lutas pode tecer contribuições para o protagonismo dessa didática do contemporâneo. Aposto que ela tenha tendências transdisciplinares, ou mesmo rizomáticas. Sua perspectiva é a de contribuir na construção de identidades profissionais docentes menos eurocentradas, mais descolonizadas e movida pela dinâmica das diferenças.

Na certeza desse rumo que a didática vem tomando, pelo menos desde o início dos anos 2000, é que dediquei meus estudos de doutoramento em pesquisa-ação com professores da educação básica exercitando práticas pedagógicas sensíveis a processos de descolonização e de implementação de temas pela educação das relações étnico-raciais. O resultado foi que o coletivo envolvido na pesquisa desenvolveu práticas que me possibilitou elaborar o que convencionei chamar de uma didática para a pretagogia. A tese sobre a valorização da cosmovisão africana na escola é escrita em formato de contos afro-brasileiros, onde os personagens representam a pesquisadora. No tópico "uma didática para a pretagogia" há o seguinte diálogo entre os personagens erês Zica, Dadá e Macu:

Macu - Mas vocês sabem que eu gosto de imaginar ser professor. Gosto de brincar de escola, de dar aula. Um dia desses, o professor Príncipe disse que eu levo jeito. Que eu tenho muita manha, muita mandinga na minha didática. Eu acho que ele quis dizer que eu sei ensinar.

Interessante, Macu! - respondi eu, dizendo ter ele um saber muito importante e fundamental na formação de professores: o saber didático.

- Essa é uma das coisa que se aprende pra ser professor, Dadá? - Respondi à Zica que sim. Na universidade, há o que chamamos de educação inicial. Os alunos devem aprender um conjunto de conhecimentos especializados que os tornam capazes de ensinar. A didática é um entre esses vários conhecimentos.

- Bom, eu acho que essa tal formação de professores é tentar fazer de alguém um griot. É sim, um mais velho que sabe ensinar, pois um griot tem essa facilidade (MEIJER, 20 I2, pp. 55-56).

A didática concebida pela influência direta da pretagogia é a teoria do ensino capaz de formar para a docência a partir de princípios afrocentrados, e tem como exemplo a conduta do griot. Dito de outra forma, a didática orientada por princípios afrocentrados é a teoria do ensino que emerge de fundamentos 
enraizados em saberes das culturas africanas, tendo como espelho as ações dos griot. Docentes são os mais velhos abundantes de sabedorias que guiam as comunidades ou coletivos de aprendizagem.

\subsection{Saberes docentes ancestrais}

Uma das teorias expressivas no campo da Didática é a de que a profissão docente requer saberes especializados. Defendem essa tese: Farias et al. (2008); Meijer (20 I2), dentre outros. Ensinar é ação de profunda interação humana orientada por profissional prévia e constantemente instruído e capaz de organizar práticas pedagógicas com potencial formativo.

Alguns estudiosos da teoria sobre o ensino descrevem os principais saberes docentes especializados em categorias que são bem parecidas. Para Selma Garrido Pimenta (1999) são eles: saberes do conhecimento, pedagógico e de experiência. Tardif (200I) denomina os saberes das formações profissionais, disciplinares, curriculares e de experiência. E para Gauthier (1988), os saberes docentes são disciplinares, curriculares, das ciências da educação, de tradição pedagógica, experienciais e de açãopedagógica.

No bojo das reflexões, considero de expressiva relevância a obra do pedagogo Paulo Freire ( 1996 ) intitulada "Pedagogia da autonomia: saberes necessários à prática educativa". O pensamento de Freire instiga a refletir sobre que conteúdos são indispensáveis à formação docente para o exercício de uma Pedagogia da autonomia na educação da/o aluna/o.

A partir dos meus mais velhos, ou seja, daqueles que chegaram antes de mim e elaboraram estudos relevantes sobre a didática, em especial acerca dos saberes necessários à docência, ouso contribuir fazendo algumas considerações. Em primeiro lugar, acho fundamental lembrarmos que a prática profissional docente se transforma com o tempo, assim como a história e a sociedade. Segundo, é preciso considerar o processo de ensino-aprendizagem como uma ação enraizada em seu contexto cultural. Terceiro, na relação entre aprendente, ensinante e currículo há uma atualização automática de percepção do que fazer pedagógico. Em quarto lugar, para além do domínio do cognitivo, ou seja, dos mecanismos mentais da percepção e da mente, os saberes docentes devem estimular também o domínio de conhecimentos sobre si, sobre o outro, e o corpo também é importante no processo de ensino-aprendizagem. Em quinto e último lugar, acrescento que o saber docente de tipo ancestral deve ser considerado na formação docente como necessário ao professorar na contemporaneidade.

O saber docente ancestral torna consciente ao profissional do ensino a necessidade de preservar nossa conexão com as tradições, pensamentos, costumes, tecnologias, dentre tantos outros conhecimentos, criados pelos nossos antepassados, dando ênfase aos conhecimentos dos ancestrais 
indígenas e africanos, por terem sido silenciados, desvalorizados, pelos mecanismos da escravização criminosa e da colonização.

A partir desse chão reflexivo é que venho professorando e pesquisando no campo da teoria do ensino acerca dos saberes especializados do profissional da educação. No tocante aos saberes ancestrais, venho dando ênfase, nas práticas de ensino e na pesquisa, para a valorização dos saberes docentes ancestrais africanos e afro-brasileiros.

\section{METODOLOGIA}

No fluxograma do curso de Pedagogia, o componente curricular didática nos países da integração está no quarto semestre. A componente possui sessenta horas divididas em três unidades. Em geral temos discentes de três, ou quatro nacionalidades matriculados. Essa diversidade é uma variável importante a se levar em consideração, uma vez que ela orienta os lugares de aprendizagem a se considerar na metodologia.

A primeira unidade curricular se dedica aos fundamentos da didática nos países da integração. Apresentamos os conceitos: educação, ensino, aprendizagem, didática, Pedagogia, instrução. A segunda unidade objetiva a construção da identidade profissional docente e o estudo dos saberes docentes necessários ao professorar. A terceira e última unidade se dedica ao entendimento da necessidade da organização do trabalho docente como prática política, técnica e pedagógica. Os conteúdos de todas as unidades são planejados em perspectiva afrocentrada. Existe também constante cuidado para se conduzir a formação da/o pedagoga/o para o exercício da docência considerando o princípio da territorialidade observado na pretagogia, ou seja, que a formação dos estudantes estrangeiros leve em consideração a educação de seus lugares de origem.

Para o alcance desse trabalho selecionamos o conteúdo teoria dos saberes docentes ancestrais, presente na segunda unidade da componente curricular para o detalhamento metodológico de seu ensino.

\section{I O trato metodológico dado ao conceito saberes docentes ancestrais no ensinar}

A metodologia utilizada está amparada nos princípios da afrocentricidade e da pretagogia. Coloco entre parênteses os princípios que mais se destacam em cada prática pedagógica apresentada. A seguir, o trato metodológico empregado no conteúdo saberes docentes ancestrais situado na II unidade curricular: 
a) Avaliação diagnóstica ( $\bigcirc$ princípio da corporeidade): em círculo e com música suave, alongar o corpo fazendo exercícios de respiração. Um convite para o corpo se permitir aprender. De olhos fechados e deitados ao solo, pedir que os discentes inspirem e expirem. Pedir que regressem aos tempos de escola desde a infância e que reflitam: Qual o lugar das tradições de seus antepassados nas práticas pedagógicas de seus professores? Solicitar que registrem em seus cadernos as reflexões em torno da indagação. Abrir para socialização.

b) Aprofundamento da aula (princípio da circularidade): considerando a sala de aula como um coletivo de aprendizagem, ou como uma comunidade onde todos devem se manifestar e contribuir com o tema gerador da aula, desenvolver, detalhar o conceito de saberes docentes de tipo ancestral. Retomamos a discussão de saberes especializados da docência a partir de alguns autores, como Pimenta (1999). Recuperamos a ideia da docência como profissão inspirada no papel do griot na tradição africana, da tese de Meijer (20।2). A partir da avaliação diagnóstica, que vem nos mostrando que a escola nos países que passaram por processo de colonização ainda valorizam sobremaneira o modelo de escola do colonizador, justificamos a necessidade de se desenvolver os saberes ancestrais na formação do professores. Uma espécie de fundamento de combate a colonização dos corpos, das mentes, da vida.

Após o aprofundamento teórico, onde todos se colocam em pé de igualdade, o coletivo é dividido em grupos para os exercícios em torno do tema:

c) Exercício I (princípio da valorização da ancestralidade africana): o grupo é instigado a listar tipos de conhecimentos de suas tradições africanas ou afro-brasileiras que não são valorizados na educação formal e apresentar as consequências na educação dos alunos/as. É importante garantir que todos os países se apresentem.

d) Exercício II (Princípio do auto-reconhecer-se afrodescendente ou africano): criar em coletividade um dispositivo didático para ser aplicado na educação básica que exercite a identidade afrodescendente ou africana;

e) Exercício III (princípio da religiosidade de matriz africana): solicitar que os grupos produzam atividades didáticas de pesquisa para a educação básica sobre as religiões de matriz africana. Considerando as notícias da mídia sobre intolerância religiosa, artigos de estudiosos, documentários.

f) Exercício IV (princípio da tradição oral): pedir que os discentes montem um pequeno espetáculo utilizando-se da tradição oral aprendida com os antepassados, como valor a se considerar nas práticas pedagógicas para a educação básica. 
g) Exercício $\vee(\bigcirc$ lugar social historicamente atribuído ao negro): apresentar obras da literatura africana e afro-brasileira feitas por nossos antepassados na perspectiva de valorização da ancestralidade.

h) Síntese da aula (princípio da circularidade): abrir círculo de debate com a seguinte indagação: que pode o saber docente ancestral?

\section{RESULTADOS E DISCUSSÕES}

A inclusão do conceito saber docente ancestral na formação de professores tem rendido alguns resultados que considero extremamente relevantes na formação dos alunos das licenciaturas da Unilab. Na avaliação diagnóstica sobre a temática, algumas discussões se destacam. Como por exemplo nas vozes de uma aluna de Cabo Verde: "Meu professor de matemática dizia que as tradições dos avós estão na contramão do progresso" (Aluna A, Turma 2017.I de letras). Uma aluna de Guiné Bissau: "Nossos livros não tratam da história e nem da geografia de nosso país. Ensinam sobre Portugal. Imagina se chegar a valorização de nossos antepassados. Isso está muito distante" (Aluna B, turma 2017.2 de Pedagogia). Em um terceiro depoimento, as vozes de um brasileiro: "Aprendemos aqui nas escolas locais que a sabedoria popular, ou dos nossos antepassados são atrasadas em relação à ciência e que devem ser desconsideradas" (Aluno C, turma 2017.2).

Em quase todos os depoimentos da avaliação diagnóstica se constata que a valorização dos saberes dos antepassados foi banida do currículo escolar e das práticas pedagógicas. Inclusive merece destaque a desvalorização dos antepassados, que são tidos como sinônimo de atraso. É importante acrescentar que, durante a exposição dos discentes, não se percebe, em geral, discordância em relação à tendência de desvalorização dos ancestrais. Inclusive há certo fortalecimento da tendência dos professores e da escola.

No entanto, é no segundo momento da aula que os alunos transformam seus pensamentos. A fundamentação teórica junto à roda de conversa vai conseguindo revelar os prejuízos que a educação contemporânea traz à formação dos alunos. Refletimos sobre a colonização, a descolonização, a Lei 10.639/2003 que versa sobre a obrigatoriedade do ensino da História e da Cultura africana e afro-brasileira da educação básica, nos amparamos nas experiências de racismo e discriminação sofridas pelos povos africanos e da diáspora e sobre a necessidade de nos mantermos enraizados em nossos territórios culturais para de lá fazermos a leitura de mundo. Os discentes facilmente concluem que as tradições, os valores transmitidos pelos ancestrais os preserva de se perderem de quem são. Esse momento é muito poderoso, porque é permeado de exemplos, de saudade de seus países, da família e do desejo de fortalecimento da conexão ancestral. 
As atividades são muito significativas para a lapidação dos saberes docentes ancestrais. Nesse momento os alunos experimentam, criam, testam no corpo, na fala, no batuque, na poesia o exercício de seus saberes de tipo ancestral. É montado um laboratório de práticas enraizadas em um tipo de saber profissional que deverá acompanhar a/o futura/o profissional. Os discentes depõem que aprenderam a criar as condições, e a metodologia para o exercício dessa modalidade de saber.

\section{CONSIDERAÇÕES FINAIS}

O componente curricular didática nos países da integração da UNILAB, objetiva contribuir com a construção da identidade profissional docente a partir de uma teoria sobre o ensino descolonizante e em perspectiva afrocêntrica. Temos convicção de que muito ainda falta para que esse seja um objetivo solidamente conquistado, uma vez que o início do curso de Pedagogia data do segundo semestre de 20 I4. No entanto, ao longo desses poucos semestres de existência, estamos investindo na progressiva solidez da base epistêmica afrocentrada e, por conseguinte, da estrutura curricular, metodológica e das práticas pedagógicas do curso.

Incluir os saberes docentes ancestrais na formação dos discentes tem se mostrado uma grande contribuição no sentido de influir na construção de um pensamento pedagógico contemporâneo que não nega a contribuição de Pedagogias populares, comunitárias, negras e subalternizadas pela colonização. Temos plena convicção de que os discentes das licenciaturas da UNILAB estão incluindo em sua formação saberes docentes de natureza ancestral para não deixarem seus mortos africanos e afro-brasileiros no esquecimento da memória e da história da educação brasileira.

\section{REFERÊNCIAS}

ASANTE, Molefi Kete. A Afrocentricidade: Notas sobre uma posição disciplinar. In: NASCIMENTO, E. L. Afrocetricidade: uma abordagem epistemológica inovadora. São Paulo: Selo negro, 2009. p. 93- 127.

CANDAU, Vera Lúcia. A didática em questão. Editora Vozes: Petrópolis, 1994

FARIAS, Maria Sabino de (et al). Didática e Docência: aprendendo a profissão. Fortaleza: Líber Livro, 2008

FREIRE, Paulo. Pedagogia da autonomia: saberes necessários à prática educativa. São Paulo: Paz e Terra, 1996.

GAUTHIER, Clermont. Por uma teoria da Pedagogia: pesquisas contemporâneas sobre o saber docente. ljuí: Unijuí, 1998. 
LIBÂNEO, José Carlos. Didática. São Paulo: Cortez, 1994.

MAZAMA, Ama. A Afrocentricidade como um Novo Paradigma. In: NASCIMENTO, E. L.

Afrocetricidade: uma abordagem epistemológica inovadora. São Paulo: Selo negro, 2009. p. I I I - I 27.

MEIJER, Rebeca de A. S. A valorização da cosmovisão africana da escola: uma pesquisa-formação com professores piauiense. 2012193 f. Tese (Doutorado em Educação) - Universidade Federal do Ceará, Faculdade de Educação, Programa Pós-graduação em Educação Brasileira, Fortaleza - Ce, 2012.

NASCIMENTO, Elisa Larkin. O Olhar afrocentrado: Introdução a uma abordagem polêmica. In: NASCIMENTO, E. L. Afrocetricidade: uma abordagem epistemológica inovadora. São Paulo: Selo negro, 2009. p. $|8|-2018$

PETIT, Sandra. H. Pretagogia: Pertencimento, corpo-dança afroancestral e tradição oral africana na formação de professores e professoras. Fortaleza:Eduece, 2015.

PETIT, Sandra H.; SILVA, Geranilde Costa e.Pret@gogia: referencial teórico-metodológico para o ensino da História e Cultura Africana e dos Afrodescendentes. Fortaleza: UFC, 201 l .

PIMENTA, Selma Garrido (org.) Saberes Pedagógicos e atividade docente. I ed. São Paulo: Cortez, 1999.

TARDIF, Maurice: O trabalho docente, a Pedagogia e o ensino: interações humanas, tecnologias e dilemas. In: Cadernos de educação, Pelotas, Rio Grande do Sul, IO(I6), p. I5-47, jan-jun.200 I.

UNILAB. Projeto político pedagógico do curso de Pedagogia. 2014. 